\title{
PRODUCTION OF A NITRATE REDUCTASE DEFICIENT STREPTOMYCIN RESISTANT MUTANT OF NICOTIANA TABACUM FOR SOMATIC HYBRIDIZATION STUDIES
}

\author{
J. D. HAMILL, D. PENTAL, E. C. COCKING AND A. J. MÜLLER* \\ Plant Genetic Manipulation Group, Department of Botany, University of Nottingham, \\ Nottingham NG7 2RD, England
}

Received 28.x.82

\section{INTRODUCTION}

We have sexually crossed an auxotrophic mutant of Nicotiana tabacum (nia-130), incapable of utilizing nitrate as the sole source of nitrogen, with a streptomycin resistant mutant of $N$. tabacum (SR1) to produce a double mutant. The nia-130 mutant lacks nitrate reductase apoenzyme activity and is a recessive nuclear mutant. As $N$. tabacum is an allotetraploid (Gray et al., 1974), mutations at two separate loci are necessary to produce nitrate reductase deficiency and thus, chlorate resistance (Müller, in press). Mutant plants were regenerated from a cell line selected for potassium chlorate resistance by a procedure previously described (Müller and Grafe, 1978). N. tabacum SR1 is a cytoplasmic mutant (Maliga et al., 1973, 1975). A nitrate reductase deficient $\left(\mathrm{NR}^{-}\right)$, streptomycin resistant $\left(\mathrm{SR}^{+}\right)$mutant will be useful for somatic cell fusion studies as hybrid colonies can be selected in culture for streptomycin resistance and the ability to use nitrate as the sole source of nitrogen.

\section{MATERIALS AND METHODS}

Nicotiana tabacum nia-130 were grown in hydroponics. The nutrient solution has the following composition: $\mathrm{KNO}_{3}, 200 \mathrm{mg} \mathrm{l}^{-1} ; \mathrm{CaCl}_{2} \cdot 2 \mathrm{H}_{2} \mathrm{O}$, $175 \mathrm{mg} \mathrm{l}^{-1} ; \mathrm{MgSO}_{4} \cdot 7 \mathrm{H}_{2} \mathrm{O}, 140 \mathrm{mg} \mathrm{l}^{-1} ; \mathrm{KH}_{2} \mathrm{PO}_{4}, 130 \mathrm{mg} \mathrm{l}^{-1}$; FeEDTA $\left(\mathrm{FeSO}_{4} \cdot 7 \mathrm{H}_{2} \mathrm{O}, 5 \mathrm{mg} \mathrm{l}^{-1}\right.$ and $\left.\mathrm{Na}_{2} \mathrm{EDTA}, 7 \mathrm{mg} \mathrm{l}^{-1}\right), \mathrm{NH}_{4} \mathrm{NO}_{3}, 350 \mathrm{mg} \mathrm{l}^{-1}$; $\mathrm{MnSO}_{4} \cdot 4 \mathrm{H}_{2} \mathrm{O}, 2 \mathrm{mg} \mathrm{l}^{-1} ; \mathrm{CuSO}_{4} \cdot 5 \mathrm{H}_{2} \mathrm{O}, 250 \mu \mathrm{g} \mathrm{l}^{-1} ; \mathrm{ZnSO}_{4} \cdot 7 \mathrm{H}_{2} \mathrm{O}$, $300 \mu \mathrm{gl}^{-1} ; \mathrm{H}_{3} \mathrm{BO}_{3}, 2 \mathrm{mg} \mathrm{l}^{-1}$ and $\left(\mathrm{NH}_{4}\right)_{6} \mathrm{MoO}_{24}, 35 \mu \mathrm{gl}^{-1}$. This nutrient solution is modified from Long Ashton nutrient solution (Hewitt, 1966). The above nutrient solution will be referred to as MN medium. $N$. tabacum SR1 plants were grown as for wild type as reported previously (Pental et al., 1982). In sexual crosses the SR 1 mutant was used as the female parent to ensure transmission of the streptomycin resistant chloroplast. Plants of the F1 were grown as for SR1. To allow segregation of nitrate reductase deficient genotypes, the F1 generation was either selfed or backcrossed to the nia- 130 parent using the F1 as the female.

Seeds from the selfed and backcrossed F1 plants were surface sterilized with 20 per cent v/v Domestos (Lever Bros. U.K.) for $45 \mathrm{~min}$ followed by thorough rinsing in sterile water. Sterilized seeds were germinated on MN medium solidified with $8 \mathrm{~g} \mathrm{l}^{-1}$ agar (Sigma) in $9 \mathrm{~cm}$ petri dishes (Sterilin, Teddington) under continuous fluorescent light (3000 lux) at a temperature

* Zentralinstitut für Genetic und Kulturpflanzenforschung, 4325-Gatersleben, GDR. 
of $22 \pm 2^{\circ} \mathrm{C}$. To select double mutant seedlings, MN medium was supplemented with $1 \mathrm{~g}^{-1}$ streptomycin sulphate (Sigma), and $2 \cdot 5 \mathrm{~g}^{-1}$ potassium chlorate. Seeds germinated within 3-4 days and after another 6-8 days the difference between chlorate sensitive and resistant seedlings was apparent. The former were shrivelled and became necrotic, the latter possessed morphologically normal cotyledons.

Potassium chlorate, streptomycin resistant seedlings were aseptically removed and cultured on a shoot culture medium (Pental et al., 1982) or were grown in hydroponics as for nia-130 mutants. Nitrate reductase activity of chlorate and streptomycin resistant plants was assayed following the general procedure of Mendel and Müller (1978). Protoplasts from chlorate and streptomycin resistant plants were isolated and cultured as previously described (Pental et al., 1982). To check for mutant traits, protoplasts were cultured in an amino acid medium with chlorate and streptomycin or a medium with nitrate as the sole source of nitrogen.

\section{Results}

\section{(i) Crosses for producing double mutant}

The progeny of crosses between SR $1 \times$ nia- 130 were resistant to streptomycin and sensitive to chlorate. F1 hybrids were selfed or backcrossed to nia-130 and the progeny were scored for segregation for chlorate sensitivity: chlorate resistance. Results are given below in tabular form.

\section{Cross}

Expected ratios sensitive : resistant

F1 selfed F1 $\times$ nia- 130

$$
15: 1
$$$$
3: 1
$$

Observed ratios sensitive : resistant

$$
\begin{aligned}
& \chi^{2} \text { at } p=0.05 \\
& 0.5>\chi^{2}>0.3 \\
& 0.3>\chi^{2}>0.2
\end{aligned}
$$

At $p=0.05, \chi^{2}$ analysis shows that deviations of observed from expected are not signficant. These results confirm that chlorate resistance is due to recessive mutations at two loci. All offspring were streptomycin resistant due to maternal inheritance of chloroplasts in Nicotiana (Kirk and TilneyBassett, 1978).

\section{(ii) Characterisation of double mutants}

Like their nitrate reductase deficient parent nia-130, seedlings of the streptomycin and chlorate resistant double mutants were unable to grow on modified $\mathrm{MN}$ medium containing $2 \mathrm{~g} \mathrm{l}^{-1}$ potassium nitrate as sole source of nitrogen. Seedlings of the nitrate reductase proficient parent SR1 were capable of growing on the modified MN medium.

When grown in hydroponics, the nitrate reductase activity of leaf homogenates of wild type $N$. tabacum was 2-3 n moles $\mathrm{NO}_{2}^{-}$produced $\mathrm{min}^{-1} \mathrm{mg}^{-1}$ protein at $18^{\circ} \mathrm{C}$. No activity was detected in leaf homogenates of nia-130 parents and of double mutant plants.

Protoplasts isolated from the leaf mesophyll tissue of double mutant plants, divided with 50-60 per cent plating efficiency when cultured in a medium containing amino acids as a nitrogen source (Pental et al., 1982). Protoplast-derived colonies were capable of growth as green colonies in amino acid medium containing $1 \mathrm{~g} \mathrm{l}^{-1}$ streptomycin sulphate, and/or 
$2 \cdot 5 \mathrm{~g} \mathrm{l}^{-1}$ potassium chlorate. However, double mutant protoplast colonies were incapable of growth in a medium containing nitrate as the sole source of nitrogen unlike protoplast-derived colonies of the wild type $N$. tabacum (Pental et al., 1982).

\section{Discussion}

Both nitrate reductase deficiency and streptomycin resistance have been used as markers for selection of somatic hybrids in culture. For example, protoplasts from a nitrate reductase deficient cell line of $N$. tabacum were fused with protoplasts of a cytoplasmic albino mutant of $N$. tabacum and somatic hybrids were selected on the basis of chlorophyll synthesis and nitrate reductase proficiency (Glimelius et al., 1981). Somatic hybrids were also selected on the basis of streptomycin resistance and hormone autotrophy by fusion between $N$. tabacum SR1 and a tumorous line of $N$. tabacum (Wullems et al., 1980).

By sexual crosses we have combined streptomycin resistance and nitrate reductase deficiency, incorporating a positive and negative selection marker in the same $N$. tabacum plant. Theoretically, this $N$. tabacum $\mathrm{NR}^{-} \mathrm{SR}^{+}$ mutant can be hybridized with any streptomycin sensitive wild type species by protoplast fusion. On selection medium containing nitrate as the sole source of nitrogen and also containing streptomycin, it is expected that only nuclear/cytoplasmic recombinant cells will be able to grow as green colonies (barring new mutations or revertants). In fusions between $N$. tabacum $\mathrm{NR}^{-} \mathrm{SR}^{+}$and other species, recombinant genomes may be expected to vary from true amphiploid somatic hybrids through a range of partial hybrids to a situation where only a chromosome carrying the nitrate reductase gene or the gene itself has been maintained in an otherwise $N$. tabacum genetic background.

The other expected recombinant cells are cybrids possessing the chloroplasts of $N$. tabacum and the nuclear genome of the chosen wild type parent. Thus the streptomycin resistant nitrate reductase deficient double mutant of $N$. tabacum will be valuable for assessing genomic compatibilities between tobacco and evolutionarily divergent species via protoplast fusion.

Acknowledgements. We thank Mr I. Gilder for technical assistance in the growth of plants, P. S. Ahuja and S. Cooper Bland for discussions. This research was supported by the ARC of the U.K., and the British Petroleum Company Ltd.

\section{REFERENCES}

GLIMELIUS, K. AND BONNETT, H. T. 1981. Somatic hybridisation in Nicotiana. Restoration of photoautotrophy to an albino mutant with defective plastids. Planta, 153, 497-503.

GRAY, J. C., KUNG, S. D., WILDMAN, S. G. AND SHEEN, S. J. 1974. Origin of Nicotiana tabacum detected by polypeptide composition of Fraction 1 protein. Nature, 252, 226227.

HEWITT, E. J. 1966. Sand and Water Culture Methods Used in the Study of Plant Nutrition. 2nd rev. edition, Commonwealth Bureau of Horticultural and Plantation Crops, East Malling. Tech. Comm. 22, Commonwealth Agricultural Bureau, Farnham Royal, England. 
KIRK, J. T. O. AND TILNEY-BASSETT, R. A. E. 1978. The Plastids. Elsevier/North-Holland Biomedical Press, Oxford.

MALIGA, P., SZ. BREZNOVITS, A. AND MARTON, L. 1973. Streptomycin-resistant plants from callus culture of haploid tobacco. Nature New Biol., 24, 29-30.

MALIGA, P., SZ. BREZNOVITS, A., MARTON, L. AND JOO, F. 1975. Non-Mendelian streptomycin resistant tobacco mutant with altered chloroplasts and mitochondria. Nature, 255 , 401-402.

MENDEL, R. R. AND MÜLLER, A. J. 1978. Reconstitution of NADH-nitrate reductase in vitro from nitrate reductase deficient Nicotiana tabacum mutants. Molec. Gen. Genet., 161, $77-80$.

MÜlleR, A. J. AND GRAFE, R. 1978. Isolation and characterization of cell lines of Nicotiana tabacum lacking nitrate reductase. Molec. Gen. Genet., 161, 67-76.

PENTAL, D., COOPER-BLAND, S., HARDING, K., COCKING, E. C. AND MÜlleR, A. J. 1982. Cultural studies on nitrate reductase deficient Nicotiana tabacum mutant protoplasts. $Z$. Pflanzenphysiol., 105, 219-227.

WULLEMS, G. J., MOLENDIJK, L. AND SCHILPEROORT, R. A. 1980. The expression of tumour markers in intraspecific somatic hybrids of normal and crown gall cells from Nicotiana tabacum. Theor. Appl. Genet., 56, 203-208. 